\title{
A Study of Psychological Morbidity among Female Sex Workers
}

\author{
${ }^{1}$ Kasthuri. Pandiyan, ${ }^{2}$ H. Chandra Shekar, ${ }^{3}$ N.R Prashanth, ${ }^{4}$ A.Gangadara \\ Psychiatric Department Bangalore medical college and research institute Bangalore
}

\begin{abstract}
The psychological distresses are higher in women in sex industry. The confluence of drug use, mental stressors, poverty, sexually transmitted diseases, low self-esteem and high-risk partners forms a fertile ground for psychological morbidity. Prostitution is associated with a host of psychosocial vulnerabilities and disadvantages [1]. Socio-demographic disadvantages like minority, ethnic status, low income, homelessness, low education level are linked with commercial sex workers [2,3].

This study was undertaken to assess the psychiatric morbidity in female commercial sex workers likely to be involved in sexual high risk taking behavior.

30 consecutive female sex workers attending the psychiatric OPD at Victoria hospital were assessed clinically after informed consent and relevant investigation. Information was collected using a semi structured proforma, MINI, Beck depression scale, Beck suicide intent scale and OT I

We observed 63\% were between 30-40 years. Abusing alcohol 100\%with tobacco 64\%. 96\% were married. $47 \%$ were illiterate. $78 \%$ were suffering from physical illness. 2 were HIV patient on treatment. $78 \%$ were having psychological morbidity. Need money for drug in $61 \%$. Money to live in $36 \%$. Husbands forced to this profession were 4\%. Easy way of earning money was 4\%. Drifted from other states with nothing else to do or people to help is 5\%.Purely survival 6\%. They all had sex with many partners and with more than 5 to six clients in a day. Very interesting is that none of them used condoms with their partners. They were not agreed by the regular partner or casual partner to use condoms. All of them practiced anal sex.10 of the clients also practiced group sex.

Our study identified the psychiatric morbidity and psycho social behavior leads to high sex behavior.
\end{abstract}

Key words: psychological morbidity; female sex workers,

\section{Introduction}

Sex work is the exchange of sex for money or drugs, has a far-reaching social, psychological, and medical consequences. Commercial sex is associated with a host of psychosocial vulnerabilities, including exposure to childhood physical abuse and childhood sexual abuse (CSA), interpersonal violence in adulthood, and substance use[1]. Sex work is often linked with socio demographic disadvantage (eg, minority ethnic status, low income, homelessness, low education level. Sex work is not always associated with substance use disorders; a strong link has been demonstrated between the two [2,3]There is a strong relationship between mental ill-health and risk-taking behaviors, drug use or sexual practices among commercial sex workers [4].

Sex work and health has focused on risky sexual practices i.e, unprotected sex, sex with multiple partners and intravenous (IV) drug use. A link between high-risk behaviors and rates of hepatitis A, hepatitis C, syphilis, and human immunodeficiency virus (HIV) infections . Risk behaviors for HIV infection appear common among men and women involved in sex work.

Kelly.J.A et.al [4] in1993 suggest that the transmission of HIV and blood borne pathogens may best be explained by the exceedingly high rates of IV drug use than exposure to high-risk sexual activity alone. The exposure to violence may be a key factor in the development of chronic health conditions among this population, noting a high incidence of head injuries and gynecological problems.

Western studies show a high degree of mental health morbidity among this population. Vanwesenbeeck [5] showed that in a sample of 96 sex workers, the prevalence of depression was 73\%, post traumatic stress disorder was $30 \%$ when compared to those among female nurses $20 \%$.The mental health of sex workers consists largely of studies documenting high rates of exposure to traumatic events and posttraumatic stress disorder among women involved in sex work. Most women report being raped, physically assaulted, or threatened with a weapon during the course of their work. With an increased incidence of depression, as many as lifetime suicidal ideation, and attempted suicide.Public health concern is high due to risky behaviors that contribute to the spread of human immunodeficiency virus [6]. Mental health issues are also significant problems among this population [7]. 
Aims

Our study aims was to make an overall objective:

1) To understand does psychiatric morbidity among female sex workers leads to increase risk taking behavior in their sexual activities?

2) Does psychosocial adversities lead to psychiatric morbidity and high risk sexual behavior?

\section{Methodology}

30 eligible participants took part in the study:The majority of participants were recruited through voluntary agencies providing a service to sex workers $(n=15 ; 50 \%)$. One participant was recruited via a service for drug users. The remaining fourteen participants were introduced to the study by chain referral to participants' associates.A majority of participants $70 \%$ were from Bangalore. Others were from Andra Pradesh, Kerala, and parts of Karnataka. All participants were asked to register their understanding and consent to participate in the study by oral consent signed in the form by an impartial witness.

Interviews were conducted at Victoria hospital Bangalore. The interview was conducted by the principal investigator in a place which ensures visual and auditory privacy. The tool adapted was MINI as the primary tool and sections from OTI, BDI, and SDI. Each interview is expected to last for about 1-2 hours. HIV and treatment status, if infected.

Tools-

Data will be collected via a Semi structured interview.

Areas covered in the interview are summarised below.

Demographic characteristics: Age, gender, level of school and tertiary education attained, sources of income, current type of accommodation, marital status, current occupation, number of pregnancies, number of children, and details of the participant's primary carer/s until the age of 18 were collected in the demographics section.

Drug use and drug treatment: Participants were asked about age of initiation of drug use and which drug they first used, whether they had ever injected any drug and which drugs injected, age of initiation of injecting drug use and which drug they first injected, drugs used in the last 12 months, and injecting drug use patterns in the last month across different drug types.

- The Opiate Treatment Index (OTI) is a structured interview designed to provide a measure of the effectiveness of drug treatments. The OTI measures 6 treatment outcomes; drug use, HIV risk-taking behavior, social functioning, criminality, health status and psychological functioning; only selected components of the instrument were administered.

- Injection-related risk behaviour

The injecting sub-scale of the HIV Risk Taking Behaviour Scale, a component of the Opiate Treatment Index (OTI), was used to measure current injection-related risk behaviour [8].

- Mini International Neuropsychiatric Interview (M.I.N.I.) It is brief structured interview design for the major Axis I psychiatric disorders in DSM-IV and ICD-10.It is divided into modules identified by letters, each corresponding to a diagnostic category, at the beginning of each of which are screening questions corresponding to the main criteria of the disorder which is used as a screener tool in this study for comorbid psychiatric conditions (Sheehan D V et all,)9 It is a validated structured diagnostic psychiatric interview for DSM-IV and ICD-10

\section{Depression}

- The Beck Depression Inventory. (BDI- (Beck et al., 1996)10was administered to determine the presence and severity of current depressive symptoms. The BDI is a 21 item self-reported measure, designed to represent the criteria for a major depressive episode as presented in the Diagnostic and Statistical Manual of Mental Disorders Text Revision (DSM-IV TR) (American Psychiatric Association, 2000)11

\section{Suicidal Ideation}

Participants were asked about suicidal ideation, whether they had ever attempted suicide, and age at first and last suicide attempt. Data was also collected on methods of attempted suicide. Beck suicide intent scales. Sexual practices was explored and documented: (type of sex work by place or solicitation/work, anal sex, number of partners in the last week/month, condom use rates with last partner by type, instances and reasons for non-use of condoms, use of lubricants or any other vaginal/anal products, experience of violence during sex work). 


\section{Statistical Analysis:}

The dependent variables include socio-demographic, psychiatric morbidity and HIV sero and treatment status, Quantitative data was analyzed with the assistance of the software package SPSS. Descriptive statistics, t-tests, chi-square tests Regression analysis was performed with variables that are independently associated with increased risk behavior.

\section{Age}

\section{Results:}

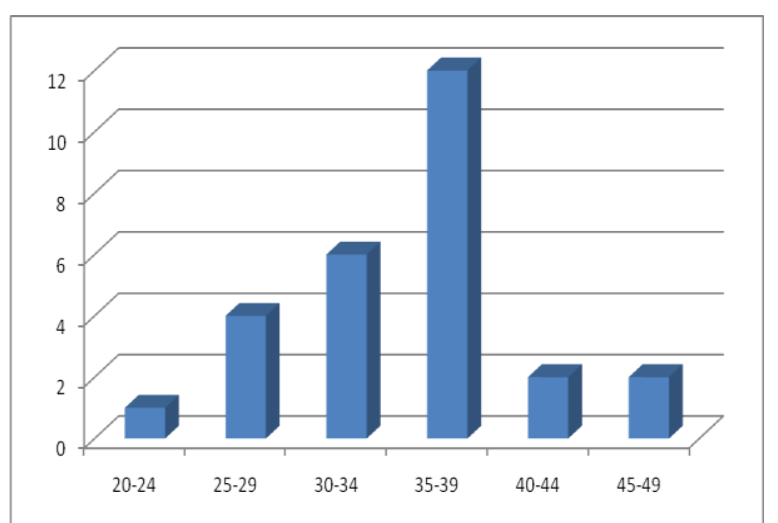

The patients were between 20 to 50 years. Half of the study population was between 30 to $40 \mathrm{yrs}$

\section{Education}

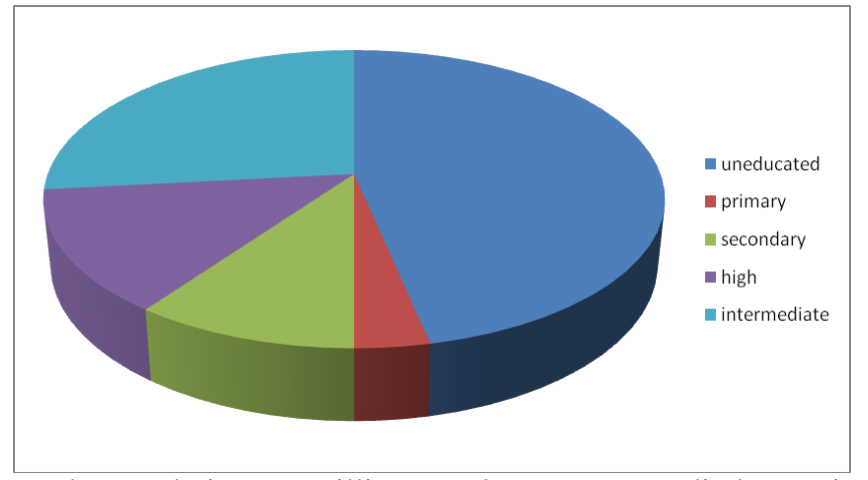

$47 \%$ of the study population were illiterate. $27 \%$ were studied up to intermediate.

\section{Marital Status}






\section{Occupation}

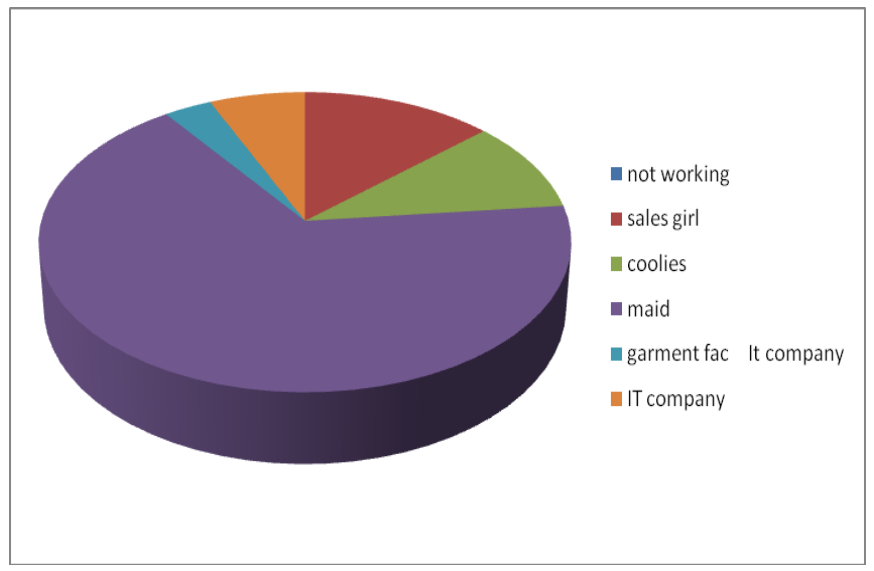

$63 \%$ were maids $.4 \%$ were sales girls in a shop $3 \%$ in were working as coolies in vegetable market. One was from garment factory and two were employed at IT company.

\section{Beck's Depression Inventory}

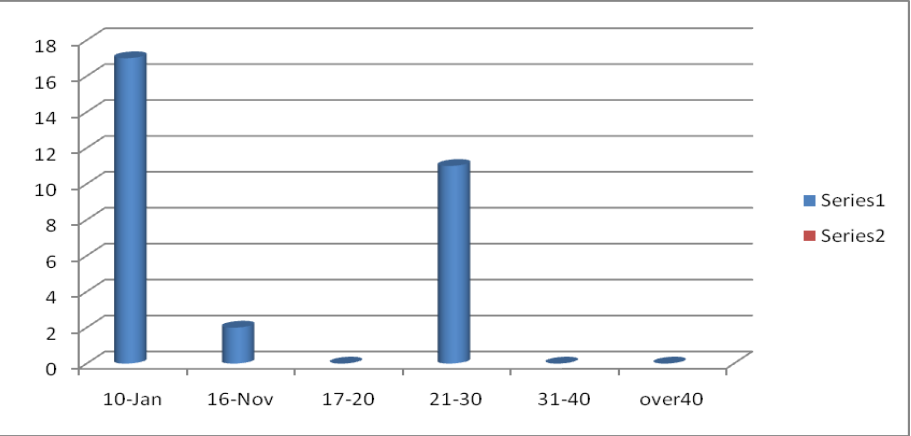

\begin{tabular}{|l|l|l|}
\hline $\mathbf{1 - 1 0}$ & NORMAL UPS AND DOWN & $\mathbf{1 7}$ \\
\hline $11-16$ & MLD MOOD DISTURBANCE & 2 \\
\hline $17-20$ & BORDER LINE CLINICAL DEPRESSION & 0 \\
\hline $21-30$ & M ODERATE DEPRESSION & 11 \\
\hline $31-40$ & SEVERE DEPRESSION & 1 \\
\hline Over 40- & EXTREME DEPRESSION & 0 \\
\hline
\end{tabular}

\section{Suicidal Indent}

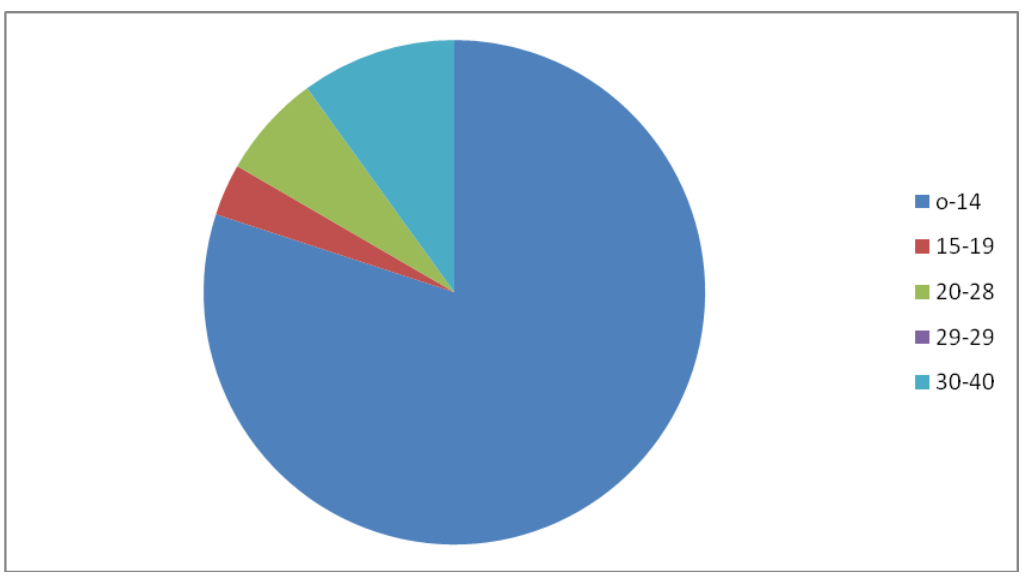




\begin{tabular}{|l|l|l|}
\hline score & & \\
\hline $0-14$ & NO INDENT- & 24 \\
\hline $\mathbf{1 5 - 1 9}$ & Low Intent & 1 \\
\hline $\mathbf{2 0 - 2 8}$ & Medium Intent & 2 \\
\hline $\mathbf{2 9 +}$ & High Intent There is also a greater risk of & 3 \\
\hline
\end{tabular}

2. Psychological Morbidity

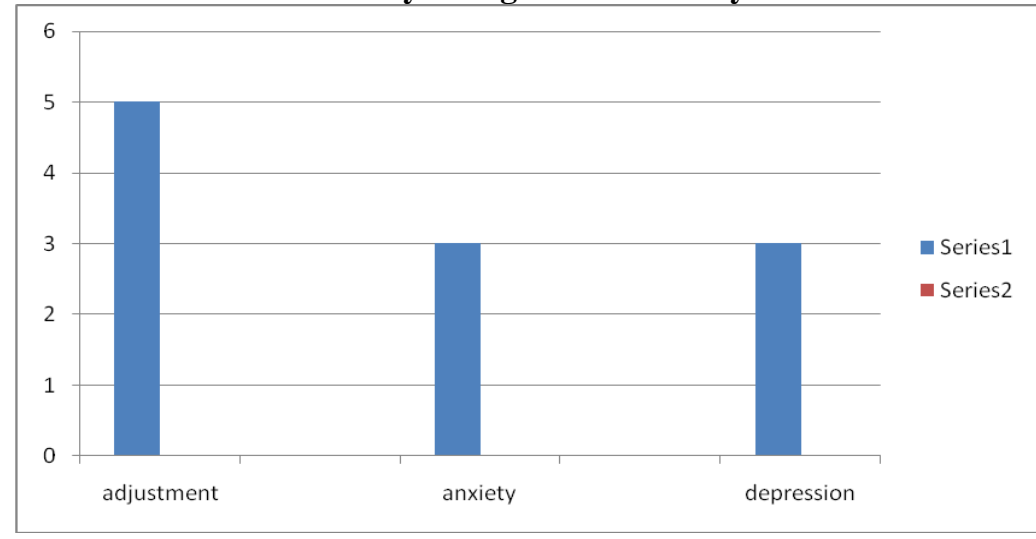

\section{Drugs}

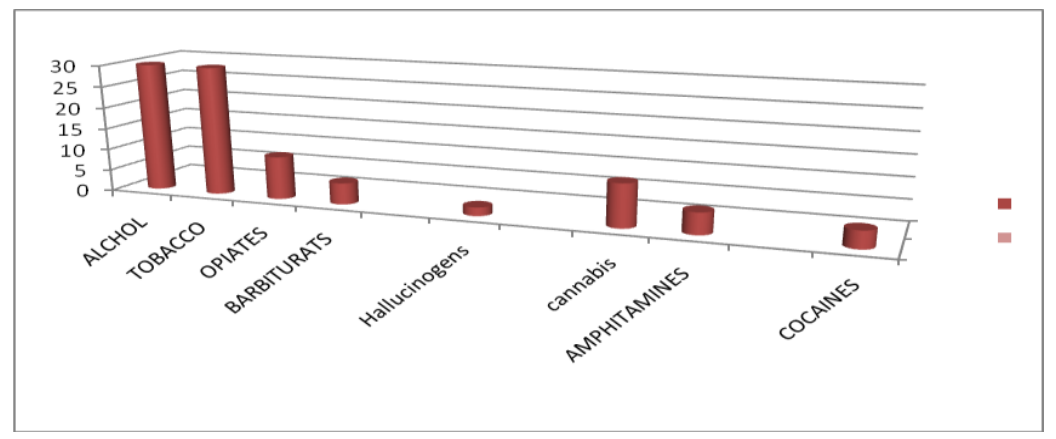

\begin{tabular}{|l|l|}
\hline Alcohol & $\mathbf{3 0}$ \\
\hline tobbacco & 30 \\
\hline Tranquillizers & 25 \\
\hline Cannabis & 6 \\
\hline Hallucinogens & 6 \\
\hline Barbiturates & 5 \\
\hline Other Opiate & 5 \\
\hline Amphetamines
\end{tabular}

Injecting Drugs

- Injection 5 of them used injection of drugs. They used three to four times in a week .They had shared the same needles more than 10 times. Sometimes they also used sterilized or disposable needless

- SEXUAL PRACTISES

- They all had sex with many partners and with more than 5 to six clients in a day. Very interesting is that non of them used condoms with their partners.they weree not agreed by the regular partner or casual partner to use condoms.

- All of them practiced anal sex.10 of the clients also practiced group sex. 


\section{Social Functioning}

\begin{tabular}{|l|l|}
\hline $\begin{array}{l}\text { different places have you lived in over the last six } \\
\text { months }\end{array}$ & $\mathbf{3}$ \\
\hline Unemployed & 0 \\
\hline Fulltime job & 0 \\
\hline Conflict with relative & many \\
\hline Conflict with patner & many \\
\hline Conflict with friends & 0 \\
\hline Support from friends & many \\
\hline Living with people injecting drugs & 5 \\
\hline
\end{tabular}

These next few questions concern the social aspects of your life (things like jobs, friends,

- $\quad$ Three of them lived in many different places have you lived in over the last six months . Non of them were un employed .No one had full time jobs.Many of them had conflict with there relative partners .The support from their friends were satisfactory. They all liked to be with their friends at least two to three were together .

- Five of them were living with their friends to share heroin injection

\section{Crime}

\begin{tabular}{|l|l|}
\hline No property crime & 0 \\
\hline No of drug dealings selling drugs to someone. & 5 \\
\hline $\begin{array}{l}\text { No of fraud- forging cheques, credit card, forging prescription and social } \\
\text { security scams- }\end{array}$ & 0 \\
\hline Crimes involving violence- & \\
\hline violence in robbery,-- & 5 \\
\hline armed robbery, assault and rape & 0 \\
\hline
\end{tabular}

- The crime refers to : property crime I mean things such as break and enter, robbery without violence,shoplifting, stealing a prescription pad, stealing a car, or receiving stolen goods.

In the study population they indulged in only 5 were indulged in shop lifting and selling drugs

\section{Medical Comorbidities:}

$\begin{array}{lc}\text { Fatique } & 3 \\ \text { Injection related problems } & 3 \\ \text { Cardiovascular } & 4 \\ \text { Respiratory } & 5 \\ \text { Genito urinary } & 25 \\ \text { Gynecological } & 6 \\ \text { Musculo skeletal } & 5 \\ \text { Neurological } & 5 \\ \text { Gastro intestinal } & 25\end{array}$

\section{Discussion:}

Age- Most of the sample $(63 \%)$ were between 30-39yrs. Age ranges of female street-based sex workers in Western countries have generally been reported to be teenage 16 years up to mid-50s, and the mean age is typically late 20 s to early30s [12,13].The older age of street-based sex workers may indicate a progression through different modes of sex work (such as escort, brothel and private work), Research in the U.K. provides support for the progression from private to street-based work among female sex workers [14]. 
Education- 50\% were illiterate. Low levels of education are also common and have not completed secondary education $[12,15]$.

Marital status- $96 \%$ were married, but only $33 \%$ were residing with their husbands.63\% were working as maids, probably this contributes due to low social support, poverty and family burden. As with the Indian studies the female sex workers were in the age group of 15 to 55 and the majority of them were between the ages of 25-35. Majority of the sex workers were poor, had low socio-economic background, often deserted by their husbands, with children and in to the profession to sustain their families.

$100 \%$ of the sample had alcohol use and $80 \%$ were on sedatives. Reasons for drinking included stress from family responsibilities, the economic burden of paying for schooling, as well as the depression associated with sex work (.Kumar MS 2003)17

- Drug /or alcohol related intoxication and the aggressive behaviour were the most important factors influencing safer negotiations for condom use and risk taking behaviour. Some settings like wine shops and brothels influenced sexual risk behaviour. Use of condoms by sex workers was less with regular sexual partners and steady partners as seen in the study by (Kumar MS 2003)17.

- Drug dependence was associated with high risk of injecting and sexual behaviors. 5 of them used injection of drugs. They used three to four times in a week. They had shared the same needles more than 10 times .Some times they also used sterilized or disposable needless

They all had sex with many partners and with more than 5 to six clients in a day. Very interesting is that non of them used condoms with their partners. They were not agreed by the regular partner or casual partner to use condoms. All of them practiced anal sex.10 of the clients also practiced group sex.

$33 \%$ had moderate depression. 10\% had high risk of suicide. Mental health problems of depression and Adjustment disorder were highly prevalent. B.Chaudhary \&Das(2001)18reported $33.3 \%$ of depressive disorders in their alcoholic sample. Health problems,psychosocial problems, economic problems and violence were all a contributing for their depression.Many of the women continue to experience mental health problems, despite access to health services, suggests that current models of service provision are not sufficient to address the problems among this group.

Many of the female sex workers interviewed for this study reported complex histories of trauma, and the majority reported experiencing work-related violence. Many of their basic needs, such as housing, were not being met and safe work practices were difficult for many

96\% were suffering from sexually transmitted diseases and two were on treatment for HIV. Poorer sex workers and ones who choose to or are forced to service high numbers of clients are at higher risk for disease. Brothelbased sex work can have fewer risks since they provide greater security than what is possible on the streets, and brothel settings are more accessible to health and education services.Positive associations between alcohol use and 'unprotected sex' causative factor for the sexually transmitted diseases [13].81\% were suffering from gastrointestinal problem which might be due to alcohol and drug related problems. Studies by Morgan [19] and Hill [20] have demonstrated the vulnerability of women to physical illness.

\section{Conclusion}

- This study is one of the first to examine the association between Psychosocial and Psychiatric morbidities leading to high risk behaviors among FSW in India. The high prevalence of Psychosocial and Psychiatric morbidities in this population suggests urgency for intervention. Psychosocial and Psychiatric morbidities are highly prevalent in this population which could be the factor implicated in high risk sexual behavior and resultant STD's.

- The public health programs targeting FSW should go beyond the focus on HIV/STI prevention and care for the fundamental health and human rights of millions of FSW in India.

- Thus, there is a need for interventions targeting Psychosocial and Psychiatric morbidities in this population.

\section{References}

[1]. Mandi L, Burnette, Lucas M, Ilgen M, Frayne SM, Mayo J, Julie C, Weitlauf. Prevalence and Health Correlates of Prostitution Among Patients Entering Treatment for Substance Use Disorders. Arch Gen Psychiatry 2008; 65: 337-344

[2]. Medrano MA, Hatch(1) JP, Zule WA, Desmond DP. Childhood trauma and adult prostitution behaviour in a multiethnic heterosexual drug-using population. Am J Drug Alcohol Abuse. 2003; 29: 463-486

[3]. Gilchrist G, Gruer L, Atkinson J. Comparison of Drug Use and Psychiatric Morbidit between Prostitute and Non-Prostitute Female Drug Users In Glasgow, Scotland. Addict Behav. 2005; 30(5):10194. El-13Bassel N, Schilling RF, Irwin KL, Faruque S, Gilbert L, Von Bargen J, Serrano Y, Edlin BR. Sex trading and psychological distress among women recruited from the streets of Harlem. Am J Public Health. 1997; 87(1):66-70.

[4]. Kelly JA, Murphy DA, Baker GR. Factors associated with severity of depression and high risk sexual behaviour among persons diagnosed with HIV infection. Health Psychol (1993) 12:215-219

[5]. Vanwesenbeeck I. Burnout among female indoor sex workers. Arch Sex Behav (2005) 34:627. [CrossRef] 
[6]. Pyett\&Warr, 1997; Shannon et al.,2008)3. Mental health issues (Burnette et al., 2008a)4 and substance abuse (Wechs-berg et al., 2009)5

[7]. Burnette ML, Lucas E, Ilgen M, Frayne SM, Mayo J,Weitlauf JC. Prevalence and health correlates of prostitutionamong patients entering treatment for substance use disorders. Arch Gen Psychiatry 2008;65:337-344.

[8]. Darke, S., Hall, W., Wodak, A., Heather, N. and Ward, J. (1992) Development and validation of a multi-dimensional instrument for assessing outcomes of treatment among opiate users: The Opiate Treatment Index., British Journal of Addiction, 87, 733-742.

[9]. Sheehan DV ET ALL ${ }^{1}$, The Mini-International Neuropsychiatric Interview (M.I.N.I.): the development and validation of a structured diagnostic psychiatric interview for DSM-IV and ICD-10.J Clin Psychiatry. 1998;59 Suppl 20:22-33;quiz 34-57.

[10]. Beck, A. T., Steer, R. A. and Brown, G. K. (1996) Beck Depression Inventory Manual, 2ndEdition, The Psychological Corporation; Harcourt Brace and Company, San Antonio.

[11]. American Psychiatric Association (2000) Diagnostic and Statistical Manual of Mental Disorders.Fourth Edition Text Revision, American Psychiatric Association, Washington D.C.

[12]. Roxburgh A, Degenhardt L, Copeland J. Posttraumaticstress disorder among female street-based sex workers inthe greater Sydney area, Australia. BMC Psychiatry2006;6:24.

[13]. Harcourt, C., and B. Donovan. (2005). The many faces of sex work. Sexually Transmitted Infections. 81(3): 201-6.

[14]. Hunter, G., May, T. and the Drug Strategy Directorate (2004) Solutions and Strategies: drug problems and street sex markets. Guidance for partnerships and providers. London: Home Office Drug Strategy Directorate.

[15]. Inciardi, J. and Surratt, H. (2001) Drug Use, Street Crime, and Sex-Trading Among Cocaine-Dependent Women: Implications for Public Health and Criminal Justice Policy, Journal of Psychoactive Drugs, 33, (4), 379-389.

[16]. Logan, T. K., Leukefeld, C. and Farabee, D. (1998) Sexual and drug use behaviours among women crack users: Implications for prevention, AIDS Education and Prevention,

[17]. Kumar MS. (2003) A rapid situation assessment ofsexual risk behaviour and substance use among sex workers and their clients in Chennai (Madras), South India. Geneva:WorldHealthOrganization. Available ahttp:www.who.int/entity/mental_health/

[18]. B.Chaudhary \&P.Das Depression in Alcoholics. Relatioship with sociodemograpic variables and abstinence: IJP(2001) Supplement vol 43

[19]. Morgan,M.Y\&Sherlock,S(1977) Sex related differences among 100 patients with alcoholic liver disease.British Medical Journal,1,939-941.

[20]. Hill,.S.Y.(1984) Alcohol problems in Women ,(Eds.) Wilsnack,S.C.\&Beckman, L.J., New York; Guilford Press. Bonomo .Y. Adolesen alcohol and other substance use: sharing the Australian experience. Ann Acad Med Singapore 2003:32: 29-35 